\title{
Exceptions as Rules of the Game for Young Adults: A Close Reading of Sonya Sones' What My Mother Doesn't Know
}

Hari Adhikari

\author{
https://doi.org/10.3126/litstud v29i01.39597
}

\section{Abstract}

Adolescents often surprise adults with their exceptional behaviors. Overwhelmed by their struggles for separating from parents, understanding the changes in the body, facing peer pressures, learning to socialize, finding a partner, and discovering one's position in the society, young adults act in "abnormal" ways. At times they even appear as if they have mad-like obsessions for exceptions. This paper digs out the major concerns of young adults and the strategies to deal with this demography implicitly proposed in Sonya Sones' novel What My Mother Doesn't Know. By using Julia Kristeva's formulations of the notions of "adolescence" and "abjection," the paper argues that the primary cause of conflicts between adults and young adults is the latter's "syndrome of ideality" and the adults' failure to understand them. Empathy from both sides is the key to mutual understanding during their struggles for self-discovery.

The rock band Paramore and its song "The Only Exception" became widely popular immediately after the single's release in February 2010. In the lyrics written by its band members Hayley Williams and Josh Farro, Hayley's vocal provides a voice to an adolescent girl who narrates an event from her childhood that has left in her an indelible impression. Seeing her father break "his own heart" and her mother swear that "she would never let herself forget" the youth promises that she will "never sing of love if it does not exist." The girl explains how she always kept a comfortable distance and found "content with loneliness." In spite of this adolescent stubbornness, she admits of being "on her way to believing in love" as soon as she finds her soulmate. Towards the end, she repeats, "You are the only exception." This repetition, eight times before revealing her belief in love, provides some clues to the understanding of young adults or the adolescent ego that drives them.

Reading young adults' minds and dealing with them is often a challenge to parents, teachers and the society at large. Adults generally approach the young adults with three main assumptions: young adults are hard to deal with; this phenomenon is equally true to both boys and girls; and the task is hard but not impossible. Fictions, especially those targeted to young adults, often depict young adults as stubborn, rule-breaking and ambivalent beings. But very few present concrete strategies for understanding and dealing with this demography. This paper attempts to dig out some of the strategies implicitly proposed in Sonya Sones' novel What My Mother Doesn't Know. By using Julia Kristeva's formulations of the "adolescent" and "abjection," the paper argues that the primary cause of conflicts between adults and young adults is the latter's "syndrome of ideality." In other words, adults make and follow rules or patterns, whereas young adults, who are both idealists and nihilists at the same time, look for exceptions apply them to their life as if they are their rules of the game. 
What My Mother Doesn't Know is a young adult novel categorized as "girl fiction" published in 2001. However, as Children's Book Reviews states, "Sophie's honest and earthy story feels destined to captivate a young female audience, avid and reluctant readers alike" (n. pag.). The novel details the experience of a fourteen year-old freshman called Sophie Stein who discovers herself in her search for "Mr. Right." When the novel begins, Sophie is hopelessly in love with Dylan, and can't get enough of him. The attraction is very physical, and Sophie, very insecure, attempts to conform to all of Dylan's wishes. But slowly, their relationship begins to flicker out, and Sophie finds herself drawn to an unknown male online named Chaz, with whom she tries to connect on an emotional level. At the same time, she is oddly attracted to an ugly, skinny, loner named Murphy whom she wants to kiss only for an adventure. Ultimately, Sophie also breaks up with Chaz who turns out to be a sexual pervert and grows closer to Murphy, who, on the other hand proves to be an incredible artist. With Murphy, she connects truly on a personal and emotional level. They grow closer and closer, until they fall for each other. Love between Sophie and Murphy eventually blooms to the extent that Sophie decides that Murphy is her "Mr. Right" because he knows who she really is, and he loves her for that. She, likewise, sees wonderful things in Murphy that no one else does. The novel ends with them staying connected, no matter what anyone else in school thinks of them.

Adolescents like Sophie often surprise adults with their exceptional behaviors. In an article "Adolescence, a Syndrome of Ideality" published in Psychoanalytical Review in 2007, Julia Kristeva presents various behavioral traits of adolescents by beginning her analysis with a review of Freudian notion of polymorphism. "Polymorphism" Kristeva writes, "is at the crossroads of the autoerotic drive and the quest for an object relation - the object of desire becomes an object of language and thought; the polymorphous perverse child is a subject of epistemophilic curiosity; the polymorphous perverse child is a seeker of knowledge (emphasis in the original, 717). According to Kristeva, the child in polymorphously perverse stage wonders at the source of his origin and creates sexual theories based on the key question: "Where do children come from?" This simultaneous process of questioning and thinking continues through the stage of latency, the gateway into adolescence. Adolescence is, thus, "the continuation of "polymorphous perversity" of the child but not a complete escape from it (Kristeva 715). "The adolescent is not a researcher in a laboratory, he's a believer," Kristeva continues, "we are all adolescents when we are enthralled by the absolute (emphasis in the original, 717). Although the notion is derived from Freud, Kristeva argues, Freud did not preoccupy himself with adolescents because he was himself a firm nonbeliever. Kristeva even considers Freud to be "the most irreligious human that ever existed." However, when he uses the term "faith" he implies a passion for the object relation that is strongly found in adolescents. When the passion for the object relation is reversed, it gives way to punishment and self-punishment. Kristeva adds, "Faith is potentially fundamentalist, as is the adolescent. Romeo and Juliet are excellent examples of this" (717). Adolescent heroes, fundamentalist in their belief patterns, suffer from both punishment from the society and self-punishment due to the reversal in their object relation.

Secondly, the adolescent subject whose statute is rooted in polymorphous 
perversity, separates from the parental couple by replacing it with a new model. In doing so, Kristeva argues, "the narcissism of the ego, tied up with its ideals, overflows the object, giving way to the amorous passion specific to the driveideality intrication" (emphasis in the original, 718). Because he believes that the other, surpassing the parental other, not only exists but also provides him with absolute satisfaction, the adolescent believes that the Great Other exists and is pleasure itself. "The slightest disappointment of this ideality syndrome casts him into the ruins of paradise and heads him toward delinquent conduct" (Kristeva 719). Irrespective of the impediments from social institutions in the name of rules or patterns, the adolescent heroe (which refers to both male and female) chases his quest for the Ideal Other even if it involves being outcast by peers or parents.

Thirdly, at a specific moment of growing up, the adolescent gets disillusioned from the childhood idealization of parents and tries to escape from it. Then the subject persuades himself that there is "another ideal for him, either a partner, husband or wife or a professional-political-ideological-religious idealan ideality already established in the unconscious" (emphasis in the original, Kristeva 720). The adolescent unconscious is therefore an ideality. Kristeva adds, "An absolutely satisfying other must exist-and does exist: Such is the adolescent's faith and unconscious passion (emphasis in the original, 720). The adolescent assumes "that ideality exists (in the unconscious), yet 'he' or 'she' disappoints me or I miss them; thus I have no choice but to take it out on myself" (720). This (mis)recognition explains why mutilation and self-destructive behavior follow the state of depression. Thus, adolescent belief is intrinsically mixed up with adolescent nihilism.

Fourthly, the adolescent's fanatic belief in the absolute partner and absolute satisfaction stabilizes the subject to the extent of madness. This stabilization can be very dangerous because it is the result of the softening of the super ego under the pressure of his/her desires. Kristeva further writes:

Situated halfway between the imaginary scenario enacted by desire and madness, the belief is not in itself delirious but harbors madness as a potentiality. The disentanglement of drive and ideality under the pressure of an increased drive frustration encourages this potentiality for madness. .. . He can fall prey to the defensive explosion of mad speech and acts leading to schizophrenia, not only because of this relaxing of psychic authority but even more so because of drive stimulation fueled by the ideality syndrome. (Emphasis in the original, 720-21)

Hence, the ideality syndrome is both beneficial as well as dangerous. On the one hand, the adolescent's dedication to work in order to obtain or reclaim the Great Other can induce moral agency for social change. While on the other hand, the adolescent can resort to drugs, drinking or delinquent behavior which Kristeva defines as the "flip side of the malady of ideality" (721). According to Kristeva, "When this fantasy fails to direct the subject toward a process of sublimation (school, profession, vocation), the failure of the paradise syndrome inevitably leads to depressivity which takes the form of common boredom: 'If I don't have Everything, I get bored'; and opens the way to delinquent conduct rooted in polymorphous perversity, which attempts to relieve the boredom" (721). Trapped between ideality and nihilism, a bored 
adolescent demonstrates exceptional behavior to kill that boredom, often difficult for adults to understand.

Finally, it is the analyst's job to listen to the adolescent's need to believe and to confirm the belief in relationships. Once, adolescents visit an analyst, they need him/her to recognize their ideality syndrome. In this regard, Kristeva proposes, "We must articulate and share our understanding of it [the adolescent ideality syndrome] if we are to comprehend and accurately interpret the delinquent behavior of the adolescent in his crisis as a source of extreme jouissance-simili-paradise" (724). Once the ideality syndrome is analyzed, the source of nihilistic outlook gets automatically explained. Only then should the analyst attempt to point out the negative aspects that Kristeva defines as "the Oedipus or Orestes type revolt, of this behavior" (724).

Now, let's return to Sophie's problem. Her first issue is with the separation. She not only separates from her parents, but also breaks up with one boyfriend after another. As the novel begins, Sophie finds "Sapphire" Dylan's special name for her win over any other ways she is called. Her parents call her "Sophie Dophie" or "Soso", Zak and Danny like to call her "Couch" or even "Siphilils", but her infatuation with Dylan is so powerful that she idealizes not only the name he has given her but also his kisses, when she is making attempts to separate herself from her mother. Sophie describes Dylan's kisses as "something/ much better than kissing" (9). Kisses are kisses, but to Sophie, Dylan's kisses are the idealized versions of kissing so long as she is in love with him.

Furthermore, even the touch of the Great Other is enough to communicate the craving of the body. When Sophie meets Dylan on the corridor and they are hooked together in their "little fingers," she finds the fingers communicate with each other using a secret language of love. In no time, the corridor clatter fades away and she can hear the "whispering of [their] fingers" (7). But this idealization dwindles as soon as Chaz enters into her life as an online friend. Chaz substitutes the lack of the ideal "Mr. Right" as soon as her idealization of Danny begins to fade away. When Danny gets his hair cut, she remarks, "There's nothing left/ to run my fingers through" as if she loved him only for the long hair he had (60). Sophie's relation with Chaz does not remain far from problems either. When Chaz tells that he likes to "jerk off in libraries" for joke or real, her response is immediate. "Consider yourself permanently deleted," she types and changes her email address (110-11). Sophie's momentary idealizations of her partners and immediate break-ups are attempts to fill in the void created in her psyche by her separation from parents. This fluidity of Sophie's identity is definitely "the continuation of "polymorphous perversity" of the child Sophie still lacking the power to make a complete escape from it (Kristeva 715). The more Sophie tries to idealize her relationship, the more she encounters with "nihilism" the absence of the idealized relation and then searches for an alternative.

Sophie's reaction to Murphy is also exceptional. Murphy, the abjected loner, initially pops into her head when she is struggling with her feelings towards Dylan. "Or maybe I don't love him at all/ Or maybe I never did" (98). And then she fantasizes about loving Murphy first out of sympathy, and then for an adventure. How can one love a guy and have sympathy for his unmanly 
personality at the same time? "I wondered if a girl ever has" she says, "Or if one ever will love him" (100). Sophie wants to become the first and the last girl to love Murphy. This is exactly like what Kristeva explains as the way one's narcissism of the ego overflows the idealized object (718). Besides knowing that Murphy is a character who is both psychologically and socially abjected, she develops a psychotic attraction towards him. She wants to kiss him in order to give him a surprise. And this fantasy comes true in disguise during the Halloween dance. By sneaking inside a black dress approved by her mother, and wearing a rose "disaster" dress she had bought in the party, Sophie cherishes to dance with the boy of her dream. She says, ". . . hoping the boy bird of my dreams/ will fly by and notice me, flutter down beside me/ and ask me to dance" (122). Along with her ex-boyfriends, she meets a "masked man" in the Halloween party but remains unaware of the fact that he is none other than Murphy, the loner. When the two are engrossed in dancing with their chests meeting with each other, Sophie says, "I don't have a clue who I'm dancing with, but our bodies are acting like old friends, as though they know something we don't know" (138). She wants to dance on and on, and then kiss him but the song suddenly ends and the masked man "disappears into the crowd" (140). However, the idealization of this masked man does not end like in her earlier relationships because of the distance created by the mask.

Just as the mother fails to understand Sophie, Sophie also finds it hard to read her mother's mind. When the two pull up in front of Rachel's house, the mother kisses Sophie on the cheek and tells her to have a good time as any "normal" mother would do. But Sophie is taken aback by the mother's normal behavior even while going to a dance party. She says, "And for once / She doesn't give me the evil eye /And warn me to watch out for the boys" (127). The mother might have been taking the daughter's interest to socialize as a normal move. But Sophie's idealization of the Great Other becomes an impediment in the mother-daughter relation that prevents them from comprehending each other. As a result Sophie starts doubting at the mother's intent:

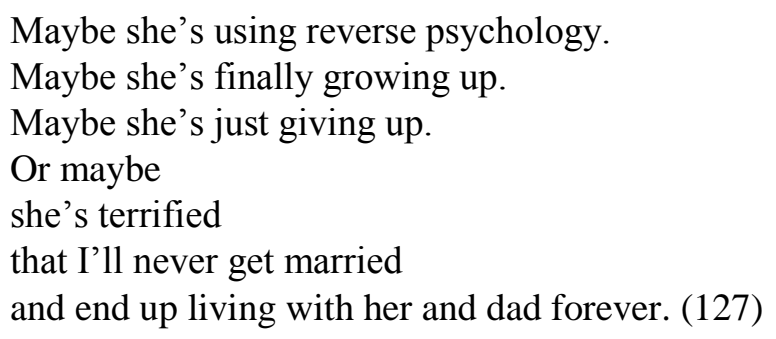

Sophie's complete failure in understanding her mother's reaction leads her to make random guesses. She remains audacious in doing what her adolescent ego dictates her. She does not feel guilty enough to rethink her decision. "A girl's got to do / what a girl's got to do" (128). And according to her adolescent ego, what a girl has to do is to chase her dreams no matter what parents think of her. Sophie even thinks that the mother should "grow up" and understand her while she is struggling with growing up herself.

Sophie's hatred of her mother is a necessary process in her selfdiscovery. So long as she loves her mother, the daughter identifies herself with the mother. But gradually Sophie develops a feeling that her mother lacks qualities of a good mother that she might have been fantasying herself of 
becoming. Sophie comes up with multiple reasons to hate her:

I hate her for being so controlling.

Hate her for being so melodramatic.

Hate her for fighting with Dad all the time

And for never once admitting

in her whole entire life

that anything could ever

possibly be her fault. (149)

The mother's controlling nature, melodramatic reaction and conflicts with her husband (Sophie's husband) are not so significant compared to her habit of never admitting her fault. Young adults like Sophie find faults in adults especially in the parent of the same sex. Freud would explain this phenomenon as the result of Oedipal difficulty, but for Kristeva, this is simply a symptom of madness in adolescents straddling between ideality and nihilism. Kristeva writes, "The disentanglement of drive and ideality under the pressure of an increased drive frustration encourages this potentiality for madness" (720). So long as the madness does not result in delinquent behavior, it is nothing but the exceptional behavior that goes beyond the adult norms and finds its own solution in the long run.

Sophie feels that her friends understand her, unlike her mother, even when they are making fun of her. Once she mentions her affair with the guy whose face she has not even seen, Rachel pokes fun of Sophie, "Fee's in love with him even though / She hasn't seen his face," Rachel adds, "Don't you see how incredibly deep that is? / She is in love with his essence" (160). But Sophie takes this comment as an appreciation. "But Rachel totally gets it," she says as if Rachael was appreciative of her move. Even if Rachel did, she is hardly different than Sophie as she belongs to the same demographic. The idealization of love, the Great Other, no matter if one has seen him for real or not, is another exceptional behavior of the young adults the novel portrays in a subtle manner.

Sophie's explanation of her thought also demonstrates the ambivalent state of her mind. "I am gray through and through," she says, "Even my thoughts are gray" (163). This grayness is nothing but the entanglement between ideality and nihilism. She even argues that if she cut her finger, she would "bleed gray blood" (163). If anyone tried to prove otherwise, she could literally cut her finger in order to satisfy her adolescent ego. Kristeva characterizes this state of adolescent mind as a causal factor that leads to self-mutilation or selfpunishment. "All childlike innocence gives way necessarily to sadomasochistic satisfaction which draws its violence from the severity" (719). Sophie is still a child in the way she floats in the clouds of fantasy.

Regarding Murphy, it takes a lot of courage for Sophie to accept him as her boyfriend. Initially, she wants to be "just friends" though she accepts the fact that he is "amazingly cool and fun to be with guy" (196). Her description of Murphy as "not exactly boyfriend material" (207) changes when Sophie discovers the real "boyfriend essence" in him. She asks Murphy if she could call him "Robin" and Murphy replies with a kiss (228-29). This is what leads to her realization that Murphy knows her essence and loves her for that. Just like the growth in Paramore's song, Sophie also realizes the meaning of love only while 
she is in love with Murphy.

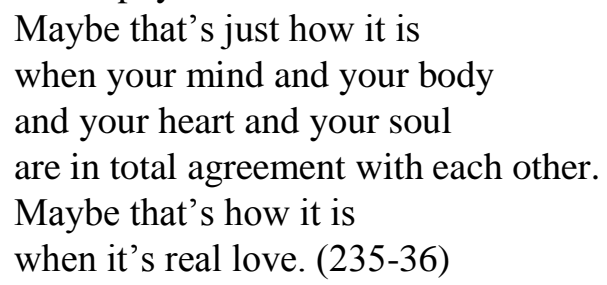

Now, what can be more idealistic than this realization? Sophie has crossed all the boundaries, from her abjection of Murphy to the peer pressure.

Finally, Sophie realizes that her mother was not a hundred percent wrong in the way she was dealing with her or living her own life. Sophie is no longer riled up by the habits of her depressed mother but develops an empathy towards her. "Listening to the silence of the musty dark, picturing myself/ sprawled on the old mattress, stuffing Hershey's Kisses in to my mouth" (249). Earlier, Sophie hated her mother for all this habit, but now this becomes not only acceptable but somehow imitable. As the mother looks at her with sad eyes, she again finds her own image in her because the mother is listening to her like an adolescent paying attention to the love story of the peer. "I suddenly find myself telling her the whole story," Sophie says, "she doesn't really say much, but it helps to know she's listening" (255). This sharing becomes possible because the mother plays the role of the analyst who listens to the client. To reiterate what Kristeva says, "It is the analyst's job to listen to the adolescent's need to believe and to confirm it. If the adolescents come to us it is because they need us to recognize their ideality syndrome" (724). The mother does exactly the same. Even when Sophie tells her about Murphy a.k.a. Robin, the mother doesn't even get mad. She just smiles and says. "I can see why" (Sones 256). The way the mother empathizes Sophie is a powerful panacea to the adolescent madness.

As we approach the end of the novel, Sophie's voice becomes mature like that of the adolescent persona in Paramore's song "The Only Exception" who conforms to the norms of the adult and begins to believe in love at the end. Through her search of the "Mr. Right" Sophie finds herself. She no longer worries about anybody's reaction to her choice of Murphy as a boyfriend. "Everything's going to be all right," Sophie says as if she is an adult trying to soothe a crying baby. And the baby is no other than her own past self that was grumpy and freaky most of the time. Sophie comes to accept adult perspective to life after having gone through a series of exceptional spasms like the fluid adolescent ego until it finds a place to settle.

Finally, What My Mother Doesn't Know provides a number of clues to the understanding of young adult sentiments. Overwhelmed by the struggles for separating from parents, understanding the changes in the body, facing peer pressures, learning to socialize, finding a partner, and finding one's position in the society, the young adults act in "abnormal" ways in the eyes of adults. At times they even appear as if they have mad-like obsessions for exceptions. Once they reveal the truths about their struggles, they even become threats to the society they live in. Even this novel was listed in the banned book in 2005 for the candid portrayal of teenage angsts, sexual content and unsuitability for teenage readers ("In Good Company", n. pag.). However, as they go through the turbulence of adolescence, and the adults patiently listen to their concerns, this 
abject age-group not only finds its own way into the adult world they develop moral agency. Hence, the novel presents a panoramic view of the way young adults navigate between ideality and nihilism and discovery themselves.

\section{Works Cited}

"In Good Company: Banned Books Week." Our Bodies Our Selves: Information Inspires Action. n. pag. 26 Sept. 2006. Web. 22 Dec. 2015.

Kristeva, Julia. "Adolescence, a Syndrome of Ideality." Trans. Michael Marder and Patricia I. Vieira. The Psychoanalytic Review, 94(5), October 2007. 715-25. Web. 2 Jan. 2016.

Paramore. "The Only Exception.” YouTube. YouTube. 4 Sept. 2010. Web. 21 Dec. 2015.

Review of What My Mother Doesn't Know. Children's Books Reviews. n. pag. Web. Accessed on 10 Jan. 2016.

Sones, Sonya. What My Mother Doesn't Know. New York: Simon Pulse, 2003. Print. 